\title{
¿Por qué es importante seguir luchando por la Educación Artística? \\ Why is it important to keep fighting for Art Education?
}

\section{María Lorena Cueva Ramírez}

\section{Lcda. en Bellas Artes}

Doctoranda Programa de Patrimonio.

Universidad de Jaén, España.

lorenacue14@gmail.com
Recibido 18/07/2016

Aceptado 17/10/2016
Revisado 19/09/2016

Publicado 01/01/2017

\section{Resumen}

La principal intención de este trabajo es poner de relieve la importancia de las artes en la Educación Secundaria. En primer lugar, y desde mi punto de vista, se muestra la forma en que la sociedad relega cada vez más las artes a la situación de lecciones complementarias y, en segundo lugar, pretendo exponer que la educación artística puede ayudar a educar, pero no sólo artísticamente sino también en la prevención de problemas reales de nuestra sociedad actual.

\section{Abstract}

The main intention of this work is to highlight the importance of Arts Education in Secondary School. First of all, and from my point of view, I show the way in which Society increasingly relegates arts to the situation of supplementary lessons and, and secondly, I pretend to expose that Arts Education can help to educate, but not only artistically if not in preventing real problems of our society current too. 


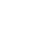

Palabras clave / Keywords

Educación, cultura visual, persona, diseño lógico.

Education, visual culture, person, logical design

Para citar este artículo

Cueva Ramírez. M. L. (2017). ¿Por qué es importante seguir luchando por la Educación Artística? Tercio Creciente, 11, págs. 151-160. DOI: 10.17561/rtc.n11.10 


\section{Un patrón mediático, a modo de introducción}

Vivimos en una sociedad de consumo, invadida por la publicidad, el marketing, y los medios de comunicación, que son los principales encargados de promover y mostrar al público las normas, pautas y cánones que el mundo de la moda establece en cada momento. En la actualidad encontramos una gran cantidad de publicidad subliminal que se escapa a nuestro control. No podemos saber hasta que punto esto nos puede provocar sentimientos de rechazo ante los bombardeos de imágenes e información, o por el contrario, el despertar admiración y curiosidad, haciendo que la información transmitida por la publicidad y los medios marquen los pasos a seguir en nuestra vida.

La publicidad y los medios de comunicación están en todas partes, van con nosotros todo el día, y nos permiten estar alerta sobre toda la actualidad que sucede en nuestro mundo, pero ¿hasta qué punto condiciona nuestro estilo de vida? ¿Marcan los medios y la publicidad nuestro comportamiento con la sociedad y con nosotros mismos?

"Esta sociedad que nos rodea es eminentemente visual, en ella la imagen tiene un papel importante. Tan importante, que "la pantalla" se ha convertido en el medio de comunicación e información más poderoso y la imagen está en todas partes. Vivimos rodeados de imágenes, un mundo de imágenes poderosas que no solo "ilustran y decoran", que "poseen significados", que no son "asépticas”..., imágenes que afectan en nuestra construcción personal y social. Hernández llega a decir “que, en cierta manera, vivimos en una era post-visual ya que las imágenes cumplen funciones que van más allá de ilustrar, ampliar visiones o construir mundos" (Hernández, 2004: 13).

La publicidad, el marketing, el mundo de la moda y los medios marcan nuestra vida y comportamiento, podemos entender hasta qué punto puede llegar la sobreexposición a los mismos, y cómo altera las conductas de aquellas personas que no han sido capaces de desarrollar un correcto y saludable juicio crítico. El poder educador de los medios que han adquirido los medios al estar tan presentes en nuestras vidas, una situación que les ha hecho poseer un poder formador y educador, sin que nosotros apenas seamos conscientes de cómo nos condicionan.

El papel de la educación artística ante esta situación es fundamental, y debemos entender cómo a través de ella podemos tratar transversalmente temas que preocupan a nuestra sociedad y a nuestro alumnado, promoviendo la educación saludable y adecuada, que ayude a un correcto y óptimo desarrollo personal, físico y mental de nuestro alumnado.

\section{Las pantallas como maestra/os}

Unos de los temas que más preocupa a los educadores actualmente es cómo los medios 
influyen cada vez más en los valores sociales de las personas.

Tal como nos señala José Martínez de Toda y Terrero (1998: 165), desde los años 30 varios teóricos interesados en el tema, hablaban del gran poder que los medios tenían para moldear la conducta de la gente ya fuera para bien o para mal. La audiencia se había convertido en una presa fácil de manipular. Aunque algunos investigadores desde los años 60 concluyeron que no es tanto el poder de los medios, sino las características "interpretativas" de la audiencia (Klapper, 1974; White, 1994). La televisión en realidad actúa a nivel ideológico promoviendo y dando mayor preferencia a ciertos significados del mundo que a otros..., y sirviendo unos intereses sociales en vez de otros. Esta labor ideológica puede ser más o menos efectiva, dependiendo de muchos factores sociales... $\leq \leq$ Efectividad $>>$ es un término socio-Dideológico, $\leq \leq$ efecto $>>$ es un término individual-- $\mathrm{conductista”} \mathrm{(Flake,} \mathrm{1987)}$

Fiske (1987: 13) señala:

"Considero la TV como un agente cultural, particularmente como provocador y circulador de significados, que sirven a los intereses dominantes de la sociedad... La televisión consiste en programas que se transmiten, en significados y placeres que se producen a causa de ellos, y en menor grado, en la forma en que se incorporan en la rutina diaria de sus audiencias». Él defiende el paradigma de la "audiencia activa».

Evidentemente quienes dirigen los medios de comunicación siempre dan unos sentidos concretos a sus contenidos. Pero eso no garantiza que la audiencia capte los mismos significados. Cada espectador crea un significado propio dentro de su contexto personal, familiar, social y dependiendo de su nivel educativo, nivel de conocimientos y de las habilidades críticas que haya desarrollado.

Investigadores, como Fuenzalida y Hermosilla (1989) destacan que las familias han situado el televisor en el centro de su hogar, utilizándolo como fuente continua de mensajes agradables, de entretenimiento, publicidad, escaparate de modelos personales y de situaciones humanas y sociales.

Los medios de comunicación disfrutan de un nivel excepcional de libertad y de autonomía. Esta libertad es vital en una sociedad democrática, una muestra de los derechos humanos dentro de nuestra sociedad. Y evidentemente, esta libertad debe de ser respetada y defendida. Aunque hay algo en lo que la gran mayoría de los investigadores están de acuerdo y es en que los medios de comunicación crean un gran impacto social, y ese impacto en ocasiones es negativo.

Estos impactos negativos en nuestra sociedad está provocando claras transformaciones actualmente, se está llegando a una “estetización” de nuestra sociedad (José Luis Brea, 2002). Evidentemente, el origen de estas transformaciones remite a las expansión de la industria audiovisual, los medios de comunicación y la iconización feroz del mundo, que está por supuesto ligada a la crecida de las industrias de la imagen, el diseño y la publicidad.

Como se explican Correa, G. R. I., Guzmán, F. M. D., \& Aguaded, G. J. I. (2000):

"En la publicidad actual se recurre a los estereotipos por un doble motivo. Primero por un imperativo netamente económico; el espacio en prensa para significar o el tiempo 
de televisión para emitir el anuncio es muy limitado y por tanto hay que recurrir a imágenes convencionales que sea descodificadas sin ningún tipo de dificultad por las audiencias. En segundo lugar, también la publicidad necesita los estereotipos como estrategia informativa porque las audiencias son emotivas antes que racionales: los signos se registran a nivel consciente pero los valores se quedan grabados a nivel inconsciente. El mensaje publicitario evita todo enfrentamiento dialéctico con las audiencias y por eso recurre al estereotipo, ofreciendo la representación de un mundo feliz e ideal donde milagrosamente la vejez, la enfermedad, los cuerpos deformes y mutilados, la lucha de clases o los problemas sociales han desaparecido por completo.”

No debemos tomar este fenómeno de "estetización” de la sociedad como algo superficial, como si las consecuencias que provoca no afectase a formas fundamentales de nuestra vida y experiencia vital, y sobre todo sobre la constitución personal que tenemos cada uno de lo real.

Vivimos en una sociedad "estetizada" que basa su proyección en el día a día de nuestra sociedad, todo lo que nos rodea cumple unos requisitos estéticos concretos, que producen en nosotros sensaciones e impresiones y nos condicionan a la hora de percibir la realidad cotidiana. Nos encontramos en la sociedad del espectáculo, dónde todo a nuestro alrededor puede llamar nuestra atención y puede hacernos cambiar la visión respecto a un tema o, incluso, respecto a nuestra forma de existir.

Como comenta Joanne Entwistle (2000):
"La moda y el vestir guardan una compleja relación con la identidad: por una parte la ropa que elegimos llevar puede ser una forma de expresar nuestra identidad, de decir a los demás algo sobre nuestro género, clase, posición, etc.; por la otra, nuestra indumentaria no siempre se puede "leer", puesto que no «habla» directamente y, por consiguiente, está expuesta a malas interpretaciones”.

En medio de esta sociedad "estetizada" encontramos EL CUERPO. En los medios de comunicación vemos imágenes de hombres y mujeres con cuerpos esculturales y perfectos, que son usados como modelos para nuestra sociedad, modelos que todos deseamos seguir y alcanzar. Encendemos la televisión y en la mayoría de los cortes publicitarios, más de la mitad de los anuncios son de cosmética, perfumes, productos para reducir peso, marcas de moda,... En estos anuncios podemos ver modelos tanto femeninos como masculinos con cuerpos que cumplen el canon marcado por nuestra sociedad. Unos cuerpos que nos han vendido como sanos y naturales, pero que sin embargo, pocos conseguimos alcanzar sin enormes sacrificios. Y lo peor de esto, es que damos por hecho que cuando consigamos un cuerpo similar al que nos muestran en las pantallas y carteles publicitarios, alcanzaremos también la plena felicidad, porque eso es lo que nos venden.

Los medios al estar tan presentes en nuestro día a día, como ya hemos visto, tienen un papel casi fundamental en el desarrollo personal de cada uno de los miembros de nuestra sociedad. En muchos casos favorecen conductas y pensamientos no del todo 
beneficiosos, y toman un papel educador de la sociedad. $Y_{i}$ es posible que los medios eduquen? En muchos casos, los adolescentes muestran más interés hacia la información dada por los medios de comunicación y la publicidad, que por la información que les facilitan los centros educativos y sus propias familias, haciendo que esa información se convierta en formación y repercuta en su educación personal.

No podemos echarle la culpa a los medios de comunicación de la situación que vivimos, ya que el principal culpable de ésta es la falta de criterio que la mayoría de adolescentes y espectadores que consumen las conductas promovidas por lo medios, han desarrollado. Este criterio ayudaría a que la información que los medios nos facilitan pueda ser filtrada, y que sólo pase a ser parte de nuestra formación personal, aquella información que consideramos útil para nuestro correcto crecimiento físico e intelectual.

Lamentablemente, gran parte de nuestra sociedad no dispone de ese filtro, y es incapaz de llevar a cabo un juicio crítico a la hora de analizar los mensajes de los medios y la publicidad. Además si a eso añadimos inseguridades alimentadas por su entorno cercano, el cóctel que se crea no es recomendable de consumir.

\section{Re-instalar la Educación Artística es re-actualizarla}

Para comprender la importancia de la Educación Artística debemos ser conscientes de que el arte ha estado vinculado al ser humano desde el principio de la historia. Supuso una forma de expresión, que le ayudaba a comunicarse y a mostrar las actividades que realizaba, utilizándolo en diversas situaciones. Todas y cada una de la expresiones artísticas que se han dado a lo largo de la historia están enriqueciendo hoy nuestra vida y cultura, y nos cuentan cómo transcurrió nuestro pasado. Presentándose el arte como un lenguaje universal.

Citado por Socorro Martín del Campo (2000) leemos como dice Herbert Read (1990) que:

"El arte es un modo de expresión en todas sus actividades esenciales, el arte intenta decirnos algo: algo acerca del universo, del hombre, del artista mismo. El arte es una forma de conocimiento tan precioso para el hombre como el mundo de la filosofía o de la ciencia. Desde luego, sólo cuando reconocemos claramente que el arte es una forma de conocimiento paralela a otra, pero distinta de ellas, por medio de las cuales el hombre llega a comprender su ambiente, sólo entonces podemos empezar a apreciar su importancia en la historia de la humanidad"

La misma autora se refiere a César Lorenzano (1982) para hacer ver que el arte le permite al artista creador poder conocerse a sí mismo, la creación de un universo propio y hermético, exteriorizar sus sentimientos y controlar de alguna forma la afectividad contenida, además de la posibilidad de producir un nuevo objeto.

Podríamos pensar que el arte, cierto arte, es un asunto de adultos, cuando en realidad no es así. Es cierto que el reconocimiento del arte infantil es más bien reciente. Muchos autores del siglo XIX como Margaret Naumburg, Florencia Cane, Rhoda Kellogg, Viktor Lowenfeld, W. Lambert, Galia Sefchovich y Gilda Waisburd, entre otros, han estudiado las características de dicho arte y 
su relación con el desarrollo y evolución de los niños y la influencia que el mundo adulto ejerce sobre ellos.

El arte infantil se dirige a la actividad creativa y artística, en tanto que el adulto no se olvida del producto, junto al proceso de creación del mismo.

Siguiendo a Socorro Martín del Campo (2000), sabemos que la educación artística desde sus comienzos pensó antes en los aspectos técnicos, como el alumnado recibía las pautas técnicas principalmente. Se les obligaba a copiar las obras de maestros consagrados, sin enseñarles a ver . Sin embargo, a partir del 1600, algunos psicólogos-pedagogos como John Lock, J. J. Rousseau y Juan Amos Commenius, dejaron claro que el arte podía servir como un elemento educativo, dejando claro los dos valores que lo formaban: el artístico-creadoremotivo y el psicopedagógico-expresióncomunicación, destacando que al ser medio de comunicación debía de conocerse tan bien como el oral y el escrito.

Por desgracia en la actualidad el estado de la Educación Artística en el nivel básico de la enseñanza ha sido relegado como ya he comentado con anterioridad. Se les ha dado prioridad a las demás materias, dejando la actividad artística como un complemento que se trabaja si queda tiempo. Los docentes apenas cuentan con preparación para abordar correctamente este área y podemos decir que no se encuentran profesores dedicados específicamente a esta asignatura. Las clases de expresión artística han quedado limitadas un alumnado que sólo puede recibirlas si asiste a talleres o los institutos preparan actividades especiales.

Como explica Socorro Martín del Campo
Ramírez (2000) el arte aporta grandes beneficios al desarrollo del niño: "Las actividades artísticas, música, pintura, danza y teatro, favorecen y estimulan el desarrollo de la psicomotricidad fina y gruesa del chico, lo cual redundará en un mayor control de su cuerpo, proporcionándole seguridad en los propios poderes y elementos para la adquisición de la lecto-escritura.”

Las actividades artísticas ayudan para las experiencias de aprendizaje escolar, motivando el desarrollo mental, ya que con éstas se aprenden conceptos como duro/suave, claro/fuerte, lento/rápido, alto/bajo, etcétera. Se ejercita la atención, la concentración, la imaginación, las operaciones mentales como la reversibilidad (al considerar varias formas para resolver una situación), la memoria, la observación, la iniciativa, la voluntad y la autoconfianza; ésta última, como un resultado de la constatación por parte del niño de todo lo que puede realizar, lo cual se traducirá en un concepto positivo de su persona, que generalizará a las actividades académicas.

El arte beneficia también el desarrollo socioemocional del niño al propiciar la aceptación de sí mismo con sus posibilidades y límites. Esta aceptación va íntimamente ligada al concepto que tenga de sí, el cual determinará su comportamiento presente y futuro: el niño se conducirá de acuerdo con quien cree que es. Desgraciadamente, muchos padres les reflejan a sus hijos una imagen negativa de su persona y, en este sentido, el arte juega el papel de un reparador para esta imagen deteriorada, manifestándose así una de sus grandes cualidades que es la terapéutica.

Asimismo, al trabajar en el seno de un grupo, el niño se enfrenta a múltiples ocasiones de interrelación en las que se 
conjugan el trabajo individual y el colectivo en un continuo dar y recibir, pedir y ceder, dirigir y seguir, compartir, cooperar y comprender las otras individualidades con sus diferencias y necesidades. Se favorece de esta manera el desarrollo moral del que nos habla Piaget.

El arte influye, asimismo, en el desarrollo estético del niño. La estética puede definirse como el medio de organizar el pensamiento, los sentimientos y las percepciones en una forma de expresión que sirva para comunicar a otros estos pensamientos y sentimientos. No existen patrones ni reglas fijas aplicables a la estética. En los productos de la creación de los niños, el desarrollo estético se revela por la aptitud sensitiva para integrar experiencias en un todo cohesivo. Esta integración puede descubrirse en la organización armónica y en la expresión de pensamientos y sentimientos realizada a través de las líneas, texturas y colores utilizados.

Por último, el arte favorece enormemente el desarrollo creador del niño, motivándolo a la flexibilidad, la fluidez, la originalidad, la independencia, la crítica y la autocrítica. $\mathrm{Al}$ crear se ponen en juego habilidades de análisis, de selección, de asociación y de síntesis, así como las experiencias y conocimientos del niño; todo lo cual da lugar a un producto nuevo, que ha adquirido vida por la voluntad y actividad de éste.”
En definitiva es preciso todavía que el arte tenga un lugar importante dentro de la educación ya sea escolar, social e incluso familiar. Debemos tener en cuenta que con ello se podrá favorecer sobremanera el presente y futuro del niño, sea en el ámbito que sea, a través de las vivencias que les aportará el arte desde muy temprana edad. Se trata de una alternativa realmente valiosa que encontramos en la educación, ya que las experiencias que los chicos vivan mediante la pedagogía artística que un docente sensibilizado con la misma, pueda aportarle, ayudarán a estimular la creatividad y favorecerá a otras situaciones cotidianas dentro del ambiente escolar y familiar. Es decir, desarrollará unas capacidades y habilidades que le ayudarán a enfrentarse a los posibles problemas y situaciones que se le presenten, implicando un mejor desarrollo de pensamiento, imaginación socialización y capacidad creadora.

Para que la educación artística reciba el reconocimiento que merece y que ayude a repercutir favorablemente en el desarrollo correcto y completo del alumnado que reciba esta enseñanza, se debe procurar la integración en la educación, de manera que se trate como un área imprescindible en su formación. 


\section{Referencias}

Brea, J.L. (2002). La estetización difusa de las sociedades actuales y la muerte tecnológica del arte. En: La era Posmedia http://www.joseluisbrea.net

Correa, G. R. I., Guzmán, F. M. D., \& Aguaded, G. J. I. (2000). La mujer invisible: Una lectura disidente de los mensajes publicitarios. Huelva, Spain: Grupo Comunicar Ediciones.

Entwistle, J. (2002) El Cuerpo y la Moda Una visión sociológica. Barcelona: Paidós.

Fiske, J. (1987) “Televisión Culture”. London, Methuen.

Fuenzalida, V. y Hermosilla, M. (1989): "Visiones y ambiciones del televidente. Estudios de Recepción Televisiva”. Chile, CENECA; pp.15- 19

Hernández Navarro, M.A. (2004) “Aporías en lo real...” en Sublime: arte + cultura contemporánea $\mathrm{N}^{\circ} .13$, págs. 34-37

Klapper, J. T. «Efectos de las comunicaciones de masas. Poder y limitaciones de los medios modernos de comunicación». Aguilar, S. A. de Ediciones. Madrid, 1974.

Lorenzano, C.(1982) “La estructura psicosocial del arte”, en Siglo XII, México pp. 102-૧103.

Martín del Campo Ramírez, S. (2000), "El papel de la Educación Artística en el desarrollo integral del educando”, en Educar: revista de educación, n.15, México, Gobierno de Jalisco, pp. 8-16

Martínez de Toda y Terrero, J. (1998). El impacto moral y social de los medios de comunicación social, en COMUNICAR 10, pp. 164-170. http://issuu.com/revistacomunicar/docs/ comunicar10/165

Read, H. (1990), “Arte y sociedad”, Madrid, Ediciones Península.

White, R.A. (1994): «Audience Interpretation of Media: Emerging Perspectives», en Communication Research Trends, 3; vol. 14. CSCC. St. Louis (EEUU). 


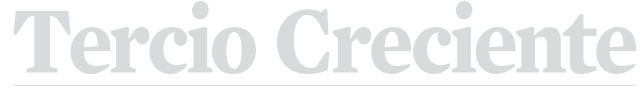

ISSN: 2340-9096

DOI: 10.17561/rtc.n11.10
Revista de Estudios en Sociedad,

Artes y Gestión Cultural

www.terciocreciente.com

http://revistaselectronicas.ujaen.es/index.php/RTC
Número 11

Enero 2017

Ensayo 